\title{
The non-existent firm: relations between corporate image and strategy ${ }^{1}$
}

\author{
Claudio Baccarani - Gaetano M. Golinelli
}

\begin{abstract}
Increasing competitiveness and changes in social expectations of firms has resulted in a growing interest in the field of the corporate image and its strategic role in the networking management of internal and external relationships. If a firm's image is positive, it may convey cohesion within the organization, and trust, credibility and legitimacy to the stakeholders. The aim of this study of the successful corporate image is to reach a definition for such an image, and possible solutions for improving it. The study concludes that an unequivocal and universal corporate image does not exist. As a result, there are as many images as there are people who interact with a company. Each person's perception is a result of the communication process, their satisfaction and the way they perceive the entire interaction. If a firm pays attention to its image, it should not conform to its interlocutors' requests or attempt to change its stakeholders' expectations; but rather, to express its culture and personality, and on the basis of its shared values, act ethically on the same wavelength as social expectations. On the contrary, if a firm cannot express its identity, it will not be able to have a specific role in society and runs the risk of not surviving in a future context, which, like the current one, is characterized by strong environmental discontinuity.
\end{abstract}

Key words: corporate image; corporate identity

"What are you doing?" my wife asked, seeing me linger, unusually, in front of the mirror.

"Nothing," I replied. "Just looking at myself, at my nose, here, inside this nostril. When I press it, I feel a little pain."

My wife smiled and said: "I thought you were looking to see which way it tilts."

I wheeled around like a dog whose tail had been stepped on.

"Tilts? My nose?"

And my wife said, serenely: "Of course, dear. Take a good look. It tilts to the right."

I was twenty-eight years old and, until then, had always considered my nose-if not actually handsome-at least quite decent, like all the other parts of my person generally².

Luigi Pirandello, One, No One and One Hundred Thousand.

1 The present contribution was published in issue n. 29 (September-December 1992) on "The economy of immaterial resources (part one)".

2 This passage is from the following translation: Luigi Pirandello [trans. William Weaver], One, No One and One Hundred Thousand, Lightning Source Inc., La Verge, TN, 1992, p. 3. 
Sinergie Vol. 33, N. 97, 2015
The formulation of proposals with competitive differentials by firms increasingly depends on intangible resources ${ }^{3}$. Among these, image occupies a prominent position. In fact, firms with a positive image enjoy a series of advantages in their internal and external relationships.

In internal relationships, a strong corporate image fosters a sense of belonging, cohesion and self-esteem in its human resources. For example, those who work for the Ferrari company feel gratified in externalizing it because of the myth that surrounds the company's history and the resulting corporate image, which spreads from the brand itself, regardless of the firm's results in Formula 1 competitions.

There is certainly no need to underline the relevance of this aspect, which takes on important motivational values, as it is crucial for the planning and realization of initiatives aiming at introducing a sense of orientation toward total quality in a company ${ }^{4}$. Moreover, if one thinks of a firm as a community of people who move in a more or less orderly fashion toward a more or less shared goal, rather than a cognitive process of knowledge production by means of knowledge $\mathrm{e}^{5}$, the magnitude of the importance of image in internal relationships becomes evident as an element of cohesion ${ }^{6}$ within a structure that is called upon to entertain intense interactions with its surrounding environment ${ }^{7}$.

Until now we have been referring to the possible impact of a firm's image in internal relationships; now it is necessary to outline the effects of its image on external relationships, intended not in the strictly technical sense of corporate functions, but rather as a network of exchanges and transactions that the firm realizes with the environment with which it interacts.

3 On this matter, Podestà observes that: "In firms there is no material resource that, in order to be used, does not require a certain amount of immaterial knowledge. On the same token, it is quite improbable that a physical good be purchased, on the market, with exclusive reference to its materiality, be it its service, image or whatever. The client purchases (and also requires) a complex good in which material and immaterial elements are interconnected in an indivisible way. There is more to it. First of all, material resources and output, considered in their pure and simple physicalness, are much more imitable and fungible if they are not 'enriched' with their immaterial elements".

4 For more on the matter, allow us to refer to Baccarani, "Qualità e governo dell'impresa", Quaderni di Sinergie, n. 7, 1991.

5 A firm may be intended as such if one considers that the "entrepreneurial function and the firm are increasingly characterized by the learning process which, to quote Sraffa, 'produces (new) knowledge as a means of knowledge (pregressa)' in a circularity that is more and more present in the systemic and evolutive theories of the firm." Cfr. E. Rullani, "La produzione del valore attraverso la conoscenza", in Atti del Convegno, Valori di capitale economico, op. cit., report summary.

6 As far as image and communication are considered elements of cohesion among the various corporate functions; see A. Touraine, "Limmagine crea unitä, Il Sole 24 Ore, 25 ottobre 1990.

7 In this sense, corporate image contributed to simplifying the management of the company as an expression of the transformation processes of the company's structure. For more on the issue of company management, allow us to refer to G.M. Golinelli, Struttura e governo dell'impresa, Cedam, Padova, 1991. 
This is the perspective within which the themes of corporate image are usually located, considered in the wide sense of product image, in connection with the brand and differentiation policies, as well as the company's institutional image as an expression of the values that are recognized by its business culture ${ }^{8}$. From this point of view it is possible to see many advantages: one of these consists in the visibility of the company and its products in a communication environment in which the crowding of messages tends to neutralize the effects of communication itself .

Equally important is the firm's acquisition of the ability to easily overcome-albeit within certain limits-the inevitable mistakes that are made in the course of relationship processes. This is one of a firm's protective functions.

However, a positive image most of all entails trust, credibility, legitimacy, and therefore the simplification of consensus-building processes ${ }^{10}$. The relevance of this aspect can be seen by turning one's attention to the ongoing changes in the client-firm relationship. In fact, "the reasons for the exchange have changed ... from being economic they tend to become increasingly psychological. The differential expectations and those of extended functionality postulate, in turn, a reinforcement of the relationship. If companies think of circumscribing their relationship with their clients to the economic area, they are mistaken. The client in fact has already extended it in terms of expectations, and his or her requests are all extra-contractual compared to the past. He or she wants to be recognized among the others and enjoy privileges and exclusive communication. He or she perceives his or her choice as a preference and thus expects to be preferred in turn. He or she is willing to give trust but demands loyalty in exchange"11.

Therefore, firms that enjoy a positive public image have the same advantages as an individual who, in the same situation, endeavors to build a series of interpersonal relations. In other words, a good image makes relationships with external subjects more fluid, particularly in the case of those who look to the firm for some reason, such as stakeholders. Just think of its significance in the "setting up" of relationships among the various independent subjects that participate in a network of firms. Just think of the

$8 \quad$ This approach is developed by Bernstein, who defines image as the perception that a subject has of the personality of a company in relation to its transmitted identity, i.e., in relation to the means that are used to make its personality emerge. Cfr. D. Bernstein, Company image, Guerini e Associati, Milano, 1988.

9 For more on the role of image in product identification processes, see L. Anolli, "Il prodotto: uno, nessuno, centomila", Il millimetro, ottobre-dicembre 1991, n. 112 .

10 Under this profile, Coda observes that "a strong image and attractiveness constitutes an intangible good of great relevance that positions itself at the centre of critical rings that lead company development, so long as the direction conceives such an image as a powerful but delicate instrument that always generates new consensus. Such consensus must be used with care, like the constant goal of an investment policy or like the focal point of an integrated system of communication that converges on it". V. Coda, "Strategie d'impresa e comunicazione: il legame mancante", Finanza, marketing e produzione, n. 1, 1990, p. 71.

11 Cfr. G. Calvi, "Dimentichiamoci del consumatore: l'appuntamento è con il cliente", Micro e macro marketing, n. 1, 1992, p. 20. 
Sinergie Vol. 33, N. 97, 2015

role of corporate image in revisiting the relationships between industry and commerce that aim toward forms of increasingly tight collaboration. And one may think, most of all, of the centrality that it acquires in the course of the passage from a contractual vision to a relational vision of its relationship with clients; in other words, from a transaction that is built on the prevailing aspects of short-term economic convenience to one founded on the continuity of exchange relationships. Such continuity is the result of the company's direction toward the transparent satisfaction of requirements that were expressed by the market from a long-term perspective, within which the firm also assumes the social role of safeguarding the client, who is a member of an organized community that seeks to guarantee the preservation of a natural environment and move within the prospect of growing quality of life.

To be clearer, it would be best to recall these concepts. The firm network and the forms of coordination between industry and commerce are organizational models that develop on the basis of structured relationships between firms that carry out different phases of a process. At the basis of the reciprocal selection among the participants first of all we find trust and credibility, followed by, if desired, metaeconomic criteria ${ }^{12}$, i.e., sensations in function of which a "deal is closed" and a "bond" is defined. Therefore, a positive image reflects trust and credibility.

If this occurs during the production process, it certainly also manifests itself in the course of the firm's final exchange with the client. Today, in the course of the exchange the relevance of contractual aspects tends to decrease, with a parallel amplification of the relational aspect founded on the interaction between the identity of the client and that of the company. The client increasingly asks for a personalization of the relationship and for the setting up of services that are capable of "solving one of his problems"13. In this sense the client tends to privilege the product's immaterial components, which are considered a group of attributes that produce utility. The security of a relationship based on the trust recognized in the sales partner is certainly co-located among these attributes because of his or her behavior and professionality.

Here, the advantages that a firm obtains from a positive image have been discussed, underlining the implicit problem of the definition of "positive image" in this context. The time has come to ask ourselves what an image is in order to try to understand how it is possible to attain a positive image. As far as this is concerned, to avoid the risks that are connected with the apparent simplicity of the topic, it would be best to follow an indirect path that is more capable of reaching the definition of corporate image through exclusion or, in other words, by defining first of all what an image is not.

12 The firm's decision-making process is impacted not only by criteria that explain objective rationality, but also by metacriteria, such as the quality of personal relationships among decision-makers. Cfr. G. Panati, "Premessa: un filo d'Arianna per lo studio delle imprese nel loro contesto", in G. Panati and G.M. Golinelli, Tecnica economica industriale e manageriale, NIS, Roma 1991, p. 99.

13 As far as this is concerned, see T. Leavitt, Marketing imagination, Milano, Sperling \& Kupfer, 1985. 
From this perspective, it is possible to assert that an "image is not..." the mere effect of promotion and advertising campaigns that are developed for a market, neither is it just the distillation of its marketing mix; rather, it is also the condensation of certain qualities that constitute a distinctive signal for the firm, its remembrance of the past and its idea of the future, as well as its style of presenting itself and remaining on the market ${ }^{14}$. Corporate image is not only the result of a company's communication process and marketing mix. It does, however, also depend on this.

The definition's negative form thus highlights the central role of communication in image formation. However, communication, as is well known, occurs between a sender and an addressee, who speak with each other by means of a message that is codified by the former and decoded by the latter in the course of a transfer process that may be obstructed by many forms of background noise. In other words, while the sender believes he is saying one thing, the addressee could-due to many reasons concerning psychological and linguistic factors or the message's technical imperfectionunderstand something else. Then again, it is clear that those who receive a message analyze it in function of their expectations and their decoding mechanisms in cognitive, affective and value terms. Thus, apart from the aspect of communication distortion, the same message decoded by different addressees may generate different image perceptions.

Corporate image is therefore nothing more than the perception that "others" have of a company. Corporate image is an invaluable asset for the company and depends not only on the company, but also on the "others". Thus, corporate image underlines an essential feature of the company's social connotation. The company, in truth, exists only because it constitutes itself as a subject that interacts with other subjects, defining the positive or negative features of the relationship during this interaction.

The above underlines how an essential aspect of corporate image consists of the conscious use of the various communication channels that the company avails itself of. In fact, companies possess an extensive range of communication channels whose real reach sometimes cannot be measured. Therefore, in order to avoid any possible misunderstanding, it is important to remember that "everything speaks" in a company. This is especially the case in service companies, because they are characterized by their direct contact with clients ${ }^{15}$. Nevertheless, the concept still holds true if it is applied to firms in general, and therefore also to industrial firms. The firm's structure, neon signs, company personnel, employed media, brand, industrial relationships, relationships with local authorities and financial statements: everything speaks. Clients and various interlocutors of the company speak, and based on their say and their word of mouth, the firm's corporate image travels. Last but not least, products with the ability to solve the problems that generate the clients' demand also speak for themselves.

14 Cfr. G. Panati, "Dal mercato al marketing", in G. Panati and M. Franch, Marketing e impresa, Cedam, Padova, 1987, p. 45.

15 This concept is well outlined by Eiglier and Langeard, who developed the pleasant example of messages that are received by a couple at a restaurant. Cfr. P. Eiglier and E. Langeard, Il marketing strategico nei servizi, McGraw-Hill, Milano, 1988, p. 133 e seguenti. 
Sinergie Vol. 33, N. 97, 2015

From this point of view, it is possible to find the space to sustain an argument that must still be verified and might appear paradoxical: in truth, the channel that "speaks less" is that of the media used for commercial and promotional purposes. This claim is further supported if one accepts a scenario of the firm's future in which roles will be strongly redefined based on the expression of a "real" -and not imaginary-ability to satisfy the demands expressed by a client who is much more watchful and rational in his course of action ${ }^{16}$. This topic is fascinating, but will be dealt with in greater detail on another occasion.

Corporate image, though, is not just the result of a communication activity or of the company's marketing mix policy: the central element in the management of the corporate image is the quality of what is given to the interlocutor to be evaluated in function of its expected quality. It is in this field that the firm acquires an identity that is not longer the result of an action upon the collective imaginary; but rather, of the expression of the ability to match the quality desired by the company's various interlocutors. Accordingly, every individual who comes into contact with the company represents a different interlocutor; however, it is possible to work out a classification that generates typical categories that are founded on the essential features that the firm's interlocutors are expecting from it.

A possible taxonomy divides these interlocutors into nine types ${ }^{17}$, which belong not only to the firm's environmental context, but also to its very structure. This is in line with the observation that there is a strong informative asymmetry among its various components ${ }^{18}$. Think, for instance, of the range of information that is available to the highest levels of management compared to non-controlling shareholders. Think, furthermore, of the information asymmetry between top managers and the company's workforce. In this context though, one enters a minefield that we will attempt to avoid, at least in the current discussion. The "mines" consist of the evaluation of the most coherent levels of the workforce's participation in the overall company decision-making process. Here, value assessments that could make the analysis "restless" could come into play.

This said, it would be best to turn back to the above mentioned classification. It divides the company's group of interlocutors, or "audiences" into nine groups: the internal audience (workforce and shareholders), the local community (citizens, authorities, institutions), groups of influence (movements safeguarding the consumer, academics, scholars), commercial interlocutors (providers, sales force, distributors), central authorities (offices in charge of various functions, ranging from

16 For more on the topic, cfr. P. Kotler, "Le implicazioni del consumerismo per gli uomini di marketing", Problemi di gestione, n. 6, 1976.

17 Cfr. D. Bernstein, Company Image, op. cit., p. 157 and ff.

${ }_{18}$ As far as informative asymmetry as an element at the base of the agency relations that are established among subjects are concerned, please refer to $S$. A. Ross, "The economic theory of agency: the principal's problem", American Economic Review, vol. 62, n. 2, 1973; M. Pilati and S. Salvemini, "Il contributo della teoria dell'agenzia allo sviluppo del capitalismo manageriale”, Giornale degli economisti e annali di economia, n. 3/4, 1988. 
industry incentives to control and taxation), mass media (newspapers, magazines, radio, television), the financial sector (banks or other institutional investors), final clients (consumers or product users) and the general public (the local collectivity in which the firm operates).

The firm more or less knowingly "speaks" with all of these subjects, through some of the previously listed channels. However, they all expect something from the firm which, although more evident and pressing in the case of the group of clients, must certainly not be neglected in relation to the other interlocutors. Firm reports recall many cases of companies that have had problems because they neglected their relationships with one or more of the other listed audiences even though they had paid the necessary attention to commercial types of audiences (clients, suppliers and banks). For example, companies have left the market due to the protests of local communities because of the heavy environmental pollution involved in the production process.

It goes without saying that the firm's first object of attention is the client, who constitutes its most prominent "patrimony"; nevertheless, it would be useful to observe how the expectations of non-commercial interlocutors are gradually assuming more importance in light of reflections on the functions of capitalist firms and on the characteristics of their social legitimization. These characteristics are becoming enriched with specific ethical content, introduced as a correction of a development mechanism based on the intensification of consumption. In such a context, the firm must endow itself with the ability to hear the voice and grasp the words of its non-commercial interlocutors, as well as perfect its ability to listen to the messages of its commercial interlocutors. As a result, throughout the range of different types of audiences, a specific company image that arises from the firm's ability to satisfy their expectations is formed. Therefore, there is not only one image, but rather as many images as there are interlocutors, or accordingly, as many as there are subjects that interact with the firm.

Indeed, within the range of different clients a multiplicity of images is generated in function of the communication the firm activates and of the assessments that customers make with reference to the relationship between their expected and perceived quality, i.e., in reference to "how they see" and "how they live out" the relationship.

In a passage in Scene II of Luigi Pirandello's play "So it is (if you think so)", Mr Laudisi and Mrs Sirelli deal with this topic. May we present it here:

- Laudisi (to Mrs Sirelli): "But whatever you do, do not tell your husband, nor my sister, nor my niece, nor Mrs... [...] how you see me, because, were you to do this, all four of them would tell you that you are wrong while, in fact, you are not at all wrong, because I am really the way you yourself see me. But this does not prevent me, my dear madam, from also being really what I am for your husband, my sister, my niece, and the lady here, Mrs..." [...]

- Mrs Sirelli: "Then do you change for each one of us?"

- Laudisi: "Of course I change, madam! And you do not, perhaps? You do not change?"

- Mrs Sirelli [precipitously]: "Ah no, no, no, no. I can assure you that I am never changing!” 
sinergie Vol. 33, N. 97, 2015

- Laudisi: "And neither am I from my point of view, believe me! And I say that all of you are wrong if you do not see me as I see myself! That is not to say that it is not quite some presumption as much on my part as on yours, dear madam".

Soon afterwards Mrs Cini joins the conversation:

- Mrs Sirelli: "So according to you, then, one can never know the truth?"

- Mrs Cini: "My, if we cannot believe even in what we see and touch!"

- Laudisi: "Yes, believe me, madam! And that is why I say: respect that which others see and touch, even if it is the opposite of what you yourself see and touch"19.

In interpersonal relationships, there is not just one point of view or one image: rather, there are as many images as the various relationships that exist. For the interlocutor, that image becomes the reality based on which he or she will formulate evaluations and make decisions. If this is typical of interpersonal relations, then it is even more so in relations among organized subjects (the firm and trade unions, for instance) and between organized subjects and individuals (the firm and its clients), since any possible confusion would increase in relation to two aspects: the plurality of the subjects that act within such organizations and the little transparency that they manifest.

It is thus possible to find situations in which a positive image is perceived within a group of equity funders and of suppliers which, on the contrary, could be negative in relation to employees and clients. This is the typical case of situations of market control that are very common in the field of public services.

Then again, it is also possible for banks to form a negative image of firms that have a very positive image for their employees and clients. This is the case for many small and medium-sized companies that are vital and technologically advanced, but weak from a financial point of view, like the numerous companies that find a banking interlocutor that only speaks the language of real guarantees but does not grasp the meaning of entrepreneurship in banking. Therefore, relationships between the firm and the various components of its environment do not generate one image, but rather lead to a plurality of corporate images, and with this, of realities. The resulting profile can be very different from the one the firm believes it possesses.

Furthermore, in this "game" the important thing is not what the firm thinks it is, so much as what the "others" think it is. Then again, is it not true that the firm does not sell what it thinks it sells; but rather, what others think they are buying?

In this context, the firm can risk finding itself at the mercy of its interlocutors. In fact, the multiplying of images could lead it to a situation in which it shows so many faces that it becomes inexpressive or resembles a portrait with deformed, or at least blurred, features. In place of "one"

19 These passages are from the following translation: Luigi Pirandello [trans. Mark Musa], So it is (if you think so) in Six Characters in Search of an Author and Other Plays, Penguin Books, London, 1995, pp. 147-148. 
there can be "many", and therefore, none. In this case, the firm can materially exist, but in reality not exist at all as a relational subject if it does not possess a specific identity that enables it to act within the spectrum of the natural multiplicity of realities that are perceived by its interlocutors. This may happen when the firm does not have a secure and precise awareness of who it is; i.e., when its company culture does not emerge to the point of revealing a personality that is expressed in a specific company identity. The latter enables the firm to communicate with its various audiences in relation to their different expectations of the firm.

Evidently, this problem becomes increasingly complex as the firm distances itself from "close audiences", such as commercial interlocutors, and moves closer to "distant audiences", such as local communities. In fact, the frequency of interactions allows essential, albeit confused, traits of a personality to emerge in everyday routines. When, instead, there is a rarefaction of relationships, in a condition in which communication is often limited to the transfer of "ritual" knowledge, it generates a condition with little transparency; as a result, the firm tends to become inexpressive and, as a consequence, "non-existent".

It is quite true that the concept expressed here is difficult. The firm, in fact, is still physically present. It may also be competitive or potentially untroubled at a certain moment. However, this will certainly change when, due to external solicitation-which, needless to say, is the rule-it will have to assume a specific role, thus discovering that it cannot do so because it is incapable of expressing its own identity.

A firm without an identity is therefore capable of surviving and prospering in an environment characterized by continuity, whereas it could encounter serious problems when facing conditions of environmental discontinuity.

Our thoughts go, for example, to the range of public services organizations, for most of which not even an artist's creativity would be enough to trace a profile. They are firms that risk disappearing-being erased-as possible forms of organizations, thus entering the immense area of historical memory. They run the risk of disappearing because they already do not exist and cannot, except in sporadic cases, transmit an identity with a specific role because this identity often does not exist and is therefore decided by the "others" for them. In this case, the political environment decides, and through it, interest groups that aim for the privatization of local public services.

However, it may also occur that a listed company, in a critical moment, be precluded from the formation processes of the values that it expresses because it is completely or greatly inexpressive ${ }^{20}$. This is not to mention the moment in which it is necessary to obtain social consensus for a productive location, manage a company crisis, and so on. The "non-existent" firm could

20 On this matter, Guatri observes how possible stock underestimates constitute one of the reasons that prevent firms' access to the stock market. "Especially in this last circumstance (the possible underestimate of stock), in a volatile market like ours that is not very sensitive toward the appreciation of substantial elements of the firm's assessment, I believe that it seems possible to endow greater weight to it (the other considered variable being loss of reservation). Starting from this goal, the firm's effort must be more serious and the communication skills that many do not possess must be demanded". Cfr. L. Guatri, "Relazione introduttiva", Atti del Convegno Valori di capitale economico, op. cit., pp. 16 e 17 del dattiloscritto. 
Sinergie Vol. 33, N. 97, 2015

therefore remain on the market until it has to face radical changes, in which case it will run serious risks of seeing its material existence cease as well.

If one considers the increasing competition that will affect markets in the future, but especially if one considers the anxiety that pervades the firm's various interlocutors in relation to a revisitation of the functions that legitimize its existence ${ }^{21}$, then the necessity of realizing, within the company, a process of image management that eludes the restricted areas of marketing and public relations, appears evident. Company image management should be a very part of the competences involved in the strategic management process of the whole firm.

Growing states of competition and changes in the profile of social expectations toward firms therefore require increasing attention to issues of company image. Such attention certainly does not entail a pursuit of the image produced by individual interlocutors, which is impossible. The firm may, in fact, control the development of the state of its corporate image but it certainly cannot abandon itself to the search for a homologous image that is generalized in the minds of its audiences. Also, attention to corporate image does not mean correcting the perceptions of various audiences in a vain and schizophrenic attempt to appear, rather than to be. All this would simply be solved in a further reduction of the visibility of the company, which would thus show no distinctive profile.

In order not to fall into the trap of the evanescent image, entrusted only to the perception of the "others" and not founded on the distinctive traits of its own personality, the company must be able to manifest the values that distinguish it in every instance of contact and with the different audiences with which it interacts. The firm will prosper the moment in which it will be able to spontaneously, and not only deliberately, express itself as a function of the cultural traits that characterize it.

The corporate image springs from the everyday routine of the relationships that each component of the company structure realizes with its interlocutors. Such a routine cannot produce positive results if it does not stem from widespread values that are shared within the organization on the basis of precise ethical principles of behavior that are in synchrony with social expectations ${ }^{22}$.

\section{References}

ANOLLI L. (1991), "Il prodotto: uno, nessuno, centomila”, Il millimetro, ottobredicembre, n. 112.

BACCARANI C. (1991), "Qualità e governo dell'impresa”, Quaderni di Sinergie, n. 7.

BERNSTEIN D. (1988), Company image, Guerini e Associati, Milano.

${ }^{21}$ On the matter, see L. Caselli, "La ri-legittimazione sociale dell'impresa", Sinergie, n. 31, forthcoming.

22 For more on this topic, see M.B. Meznar, J.J. Chrisman and A.B. Carroll, "Responsabilità sociale e management strategico: verso una classificazione delle strategie d'impresa", Problemi di gestione, supplemento al n. 5, vol. XIX. 
CALVI G. (1992), "Dimentichiamoci del consumatore: l'appuntamento è con il cliente", Micro e macro marketing, n. 1.

CASELLI L. (in press), "La ri-legittimazione sociale dell'impresa", Sinergie, n. 31.

CODA V. (1990), "Strategie d'impresa e comunicazione: il legame mancante", Finanza, marketing e produzione, n. 1.

EIGLIER P., LANGEARD E. (1998), Il marketing strategico nei servizi, McGraw-Hill, Milano.

GOLINELLI G.M. (1991), Struttura e governo dell'impresa, Cedam, Padova.

GUATRI L. (1992), "Relazione introduttiva”, in Atti del Convegno (ed.), Valori di capitale economico e valori di mercato delle imprese: quali strumenti per attuarne i divari?, Università Bocconi, Milano.

KOTLER P. (1976), "Le implicazioni del consumerismo per gli uomini di marketing", Problemi di gestione, n. 6.

LEAVITT T. (1985), Marketing imagination, Sperling \& Kupfer, Milano.

MEZNAR M.B., CHRISMAN J.J., CAROLL A.B. (1992), "Responsabilità sociale e management strategico: verso una classificazione delle strategie d'impresa", Problemi di gestione, supplemento al n. 5, vol. XIX.

PANATI G. (1987), "Dal mercato al marketing", in G. Panati, M. Franch (ed.), Marketing e impresa, Cedam, Padova.

PANATI G. (1991), "Premessa: un filo d'Arianna per lo studio delle imprese nel loro contesto", in G. Panati, G.M. Golinelli (eds.), Tecnica economica industriale e manageriale, NIS, Roma.

PILATI M., SALVEMINI S. (1998), "Il contributo della teoria dell'agenzia allo sviluppo del capitalismo manageriale", Giornale degli economisti e annali di economia, n. $3 / 4$.

PODESTÀ S. (1992), "Intangibles e valore”, in Atti del Convegno (ed.), Valori di capitale economico e valori di mercato delle imprese: quali strumenti per attuarne i divari?, Università Bocconi, Milano.

ROSS S.A. (1973), "The economic theory of agency: the principal's problem", American Economic Review, vol. 62, n. 2.

RULLANI E. (1992), "La produzione del valore attraverso la conoscenza", in Atti del Convegno (ed.), Valori di capitale economico, e valori di mercato delle imprese: quali strumenti per attuarne i divari?, Università Bocconi, Milano

TOURAINE A. (1990), "L'immagine crea unità", Il Sole 24 Ore, 25 ottobre.

\section{Academic or professional position and contacts}

\section{Claudio Baccarani}

Full Professor of Business Management

University of Verona - Italy

e-mail: claudio.baccarani@univr.it

\section{Gaetano M. Golinelli}

Full Professor of Business Management

Sapienza University of Roma - Italy

e-mail: gaetano.golinelli@uniroma1.it
Claudio Baccarani Gaetano M. Golinelli

The non-existent firm: relations between

corporate image and strategy 